MATEC Web of Conferences 51, 03006 (2016)

DOI: $10.1051 /$ matecconf/20165103006

(C) Owned by the authors, published by EDP Sciences, 2016

\title{
Component Analysis of Deposits in Selective Catalytic Reduction System for Automotive Diesel Engine
}

\author{
Neng Zhu ${ }^{1, a}$, Lin Lv ${ }^{1}$ and Chengwei Ye ${ }^{1}$ \\ ${ }^{1}$ Key Laboratory of High Performance Ship of Ministry of Education, Wuhan University of Technology, Wuhan, China
}

\begin{abstract}
In this paper, deposits in exhaust pipes for automotive diesel engines were studied by various chemical analysis methods and a kind of analysis process to determine the compositions of organic matter was proposed. Firstly, the elements of the deposits were determined through the element analysis method. Then using characteristic absorption properties of organic functional groups to the infrared spectrum, the functional groups in the deposits were determined. Finally, by GC-MS (gas chromatography - mass spectrometry) test, the content of each main component was determined quantitatively. Element analysis results indicated that the deposits adsorbed metal impurities from fuel oil, lubricating oil, mechanical wear and urea water solution. The result of GC-MS test showed that the area percentage of cyanuric acid was the biggest (about $85 \%$ ), the second was urea (about $4 \%$ ), and the content of biuret and biurea was scarce.
\end{abstract}

\section{Introduction}

Diesel engines are widely used in heavy vehicles because of its superior performance on the economy and reliability. Selective catalytic reduction (SCR) which uses urea water solution (UWS) as the reductant is widely regarded as one of the most promising technology to reduce $\mathrm{NO}_{\mathrm{X}}$ emissions of diesel engine and to meet increasingly stringent emission regulation standards [1-4]. As for SCR system in practical engineering application, however, there are still many problems to be solved, especially the deposit problem, which has brought serious challenges for the application of the SCR system.

In the ideal situation, UWS generates reductant $\mathrm{NH}_{3}$ after evaporation, pyrolysis and hydrolysis [57]. Schaber, etc. [8] studied the thermal decomposition process of urea by thermo-gravimetric analysis method in the lab. The results showed that the urea pyrolysis and the generation of related by-products are related to the temperature. When the temperature was above $152^{\circ} \mathrm{C}$, urea started to break down, and at the same time biuret would form. When the temperature was above $190^{\circ} \mathrm{C}$, a lot of cyanuric acid generated. Thagard [9] dealt with the chemical analysis of the by-products formed by urea decomposition at about $150{ }^{\circ} \mathrm{C}-200{ }^{\circ} \mathrm{C}$ in a dielectric barrier discharge (DBD). Recent researches [10-14] showed that we could get hydrogen by urea pyrolysis reaction, which was considered as a potential source of hydrogen/fuel cell power. In addition, other researchers [15-17] found urea related deposits formed at different places in vehicles with SCR system, such as the exhaust pipe wall, the surface of catalyst entrance, the inside of urea nozzle and urea pump. We also observed a large

${ }^{\text {a }}$ Corresponding author : zhuneng555@163.com

This is an Open Access article distributed under the terms of the Creative Commons Attribution License 4.0, which permits unrestricted use, distribution, and reproduction in any medium, provided the original work is properly cited. 
number of deposits existing on the exhaust pipe wall through road test for a certain type of commercial vehicle. The exhaust pipe was serious congestion, which affected the performance of diesel engine seriously. What's more, the deposits formed in diesel engine exhaust pipes after continuous injection of urea aqueous solution for $5 \mathrm{~h}$ caused exhaust back pressure increased by 1.4 $\mathrm{kPa}$ and $\mathrm{NO}_{\mathrm{X}}$ conversion efficiency reduced by $3 \%$.

In terms of SCR system for automotive diesel engine, the operation condition of the given engine and exhaust flow field is very complex, the formation of deposits is an extremely complicated physical chemistry process. In order to avoid or reduce the formation of deposits, it is necessary to study its composition. In this paper, the deposits from a vehicle diesel engine exhaust pipe wall were analyzed by various chemical analysis methods. Not only its compositions were determined, but also the content of each component in the deposits was analyzed quantitatively.

\section{Experimental}

\subsection{Reagents}

A road test was conducted using a certain type of commercial vehicle with SCR system. Technical parameters of the engine and the test vehicle are shown in Table 1 . After $1000 \mathrm{~km}$ of road test, a large amount of deposits were found on the exhaust pipe wall, as shown in Figure 1. The vehicle driving route included suburban road, plain expressway and mountain road. The collected deposits weighted $131.67 \mathrm{~g}$, which was the sample for the following chemical analysis.

Table 1. Technical Parameters.

\begin{tabular}{|c|c|c|}
\hline \multicolumn{2}{|c|}{ Parameter Name } & Parameter Value \\
\hline \multirow{3}{*}{ Vehicle } & The Maximum Allowable Total Mass & $31000 \mathrm{~kg}$ \\
\cline { 2 - 3 } & Unladen Mass & $10200 \mathrm{~kg}$ \\
\hline \multirow{4}{*}{ Engine } & Displacement & $11.12 \mathrm{~L}$ \\
\cline { 2 - 3 } & Quantity of cylinders & 6 \\
\cline { 2 - 3 } & Air Admission Mode & Supercharged Inter-cooling \\
\cline { 2 - 3 } & Fuel System & High Pressure Common Rail \\
\cline { 2 - 3 } & Rated Rotate Speed & $1900 \mathrm{r} / \mathrm{min}$ \\
\cline { 2 - 3 } & Rated Power & $257 \mathrm{~kW}$ \\
\hline
\end{tabular}

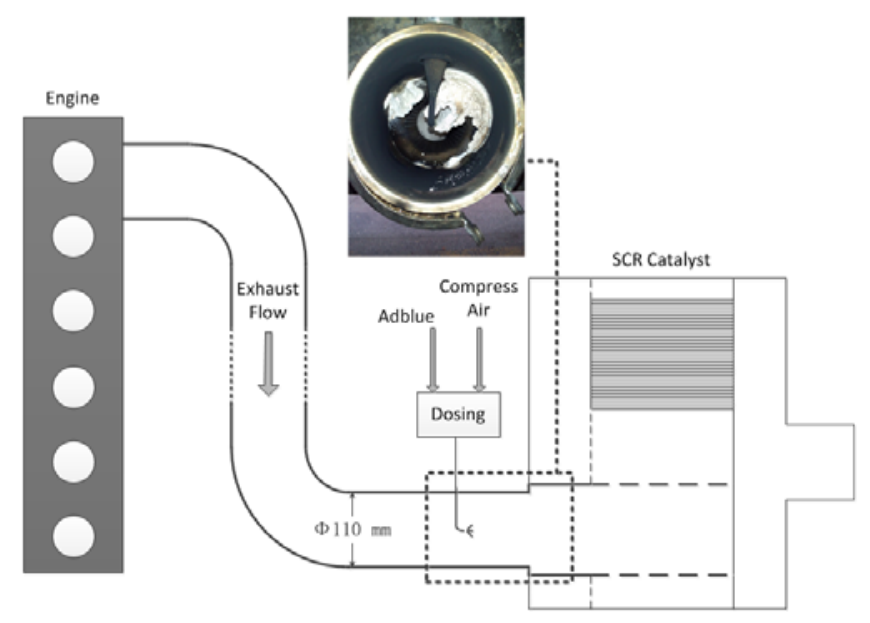

Figure 1. The deposits on the exhaust pipe wall. 


\subsection{Apparatus}

Based on the chemical and physical properties of deposits, its components were researched by chromatographic analysis, spectral analysis, spectrum analysis and thermal analysis. Chemical analysis apparatus are shown in Table 2.

Table 2. Test apparatus.

\begin{tabular}{|c|c|c|}
\hline Apparatus name & Specifications & Manufacturer \\
\hline X-ray Fluorescence Spectrometer & AXIOS & PANalytical.B.V \\
\hline Plasma Emission Spectrometer & Optima4300DV & PerkinElmer \\
\hline CHNS/O elemental analyzer & Vario EL cube & Elementar \\
\hline Fourier transform infrared spectrometer & NEXUS & Therno Nicolet \\
\hline GC-MS & Agilent 7890/ 5975 & Agilent \\
\hline
\end{tabular}

\subsection{Procedures}

Firstly, the elements of the deposits were determined through the element analysis method. According to JY/T 016-1996 type of general principle of wavelength dispersion X-ray fluorescence spectrometer method, the contents of inorganic elements in the sample were determined using Axios advanced Xray fluorescence spectrometer. In order to study the sources of the inorganic elements in the deposits, the inorganic elements contents of UWS and deposits were compared and analyzed by Optima4300DV plasma emission spectrometer. In addition, the UWS for SCR system used in the test process was provided by KeLanSu Environmental Protection Technology Co., Ltd. The deposits sample was dissolved by aqua regia and diluted with hydrochloric acid of $10 \%$ concentration. What's more, carbon, hydrogen, nitrogen, oxygen and etc. are the common elements in the organic matter. In this paper, organic elements in the sample were determined by Vario EL cube model CHNSO element analyzer manufactured by Elementar in German.

Then the deposits were analyzed using potassium bromide $(\mathrm{KBr})$ pressed-disk technique by Fourier transform infrared spectrum and the functional groups in the deposits were determined as the characteristic absorption properties of organic functional groups to the infrared spectrum.

Gas chromatography-mass spectrometry (GC-MS) technology has high detection sensitivity and good separation effect, which has become one of the most effective means to analyze complex unknown material. In this paper, the deposits were dissolved using methanol as solvent and the supernatant was collected to be analyzed by GC-MS. As a result, the content of each main component was determined quantitatively.

\section{Results and Discussion}

\subsection{Elemental analysis}

The results of x-ray fluorescence spectrum test are shown in Table 3. The loss on ignition of the sample was as high as $99.8 \%$ after burning under the high temperature of $1000{ }^{\circ} \mathrm{C}$ for $2 \mathrm{~h}$, which indicated that the main ingredients in the sample were organic matters.

Table 3. Results of x-ray fluorescence spectrum test.

\begin{tabular}{|c|c|c|c|c|c|c|c|c|c|}
\hline Elements & $\mathrm{Si}$ & $\mathrm{Al}$ & $\mathrm{S}$ & $\mathrm{Mo}$ & $\mathrm{Zr}$ & $\mathrm{Ba}$ & $\mathrm{Pb}$ & $\mathrm{Br}$ & Loss on ignition \\
\hline Contents (\%) & 0.042 & 0.033 & 0.007 & 0.015 & 0.003 & 0.016 & 0.046 & 0.038 & 99.8 \\
\hline
\end{tabular}

b. Calculated by oxide content.

In order to study the sources of the inorganic elements in the deposits, the results of plasma emission spectrum test are shown in Table 4. It is observed that the mass fraction of metal elements 
detected in the samples are higher than that in the UWS. Hence, we can infer that the deposits have absorbed metal impurities from fuel oil, lubricating oil, mechanical wear and urea water solution.

Table 4. Results of plasma emission spectrum test.

\begin{tabular}{|c|c|c|c|}
\hline Elements & Wave length $/ \mathbf{n m}$ & ${\text { Urea water solution } / \mathbf{1 0}^{-\mathbf{6}}}$ & Deposits/10 $^{\mathbf{6}}$ \\
\hline $\mathrm{Al}$ & 396.153 & 69 & 110 \\
\hline $\mathrm{Cr}$ & 267.716 & 3 & 10 \\
\hline $\mathrm{Fe}$ & 238.204 & 2 & 50 \\
\hline $\mathrm{Mg}$ & 285.213 & 0 & 50 \\
\hline $\mathrm{Mn}$ & 257.610 & 1 & 10 \\
\hline $\mathrm{Pb}$ & 220.353 & 0 & 10 \\
\hline $\mathrm{Zn}$ & 206.200 & 0 & 100 \\
\hline $\mathrm{K}$ & 766.490 & 8 & 70 \\
\hline $\mathrm{Na}$ & 589.592 & 63 & 120 \\
\hline $\mathrm{Ca}$ & 317.933 & 0 & 850 \\
\hline $\mathrm{Si}$ & 251.611 & 0 & 20 \\
\hline
\end{tabular}

The results of organic elemental analysis are shown in Table 5. At the same time, Table 5 lists the theoretical value of the content of each element in urea and related by-products .It indicates that the sample is composed of a variety of organic compounds by comparing the organic elements in the sample, urea and by-products.

Table 5. Results of organic elemental analysis.

\begin{tabular}{|c|c|c|c|c|}
\hline Elements & $\mathrm{C}(\%)$ & $\mathrm{H}(\%)$ & $\mathrm{N}(\%)$ & $\mathrm{O}(\%)$ \\
\hline Deposits & 27.26 & 2.74 & 36.33 & 32.1 \\
\hline Urea & 20 & 6.67 & 46.67 & 26.67 \\
\hline Biuret & 23.3 & 4.85 & 40.78 & 31.07 \\
\hline Cyanuric acid & 27.91 & 2.33 & 32.56 & 37.21 \\
\hline
\end{tabular}

\subsection{Qualitative analysis}

Figure 2 shows the Fourier infrared spectra of deposits. As the characteristic absorption peaks shown in Figure 2, two absorption peaks at 3466 and $3334 \mathrm{~cm}^{-1}$ respectively are the absorption bands of antisymmetric stretching vibration $v\left(\mathrm{NH}_{2}\right.$, as) and symmetric stretching vibration $v\left(\mathrm{NH}_{2}, \mathrm{~s}\right)$. Strong absorption peaks at 1778,1752 and $1721 \mathrm{~cm}^{-1}$ are the absorption bands of stretching vibration $v(\mathrm{C}=\mathrm{O})$. Absorption peak at $1605 \mathrm{~cm}^{-1}$ is the absorption band of deformation vibration $\delta\left(\mathrm{NH}_{2}\right)$. Strong absorption peak at $1053 \mathrm{~cm}^{-1}$ is the absorption band of stretching vibration $v(\mathrm{C}-\mathrm{N})$. Absorption peaks across $900 \sim 700 \mathrm{~cm}^{-1}$, whose peak type is wide and strong, is the characteristic absorption bands of wagging vibration $\omega\left(\mathrm{NH}_{2}\right)$. These characteristic absorption peaks appeared at the same time, which showed that the composition of the sample contained aliphatic amide. Its structure formula is

$$
\begin{gathered}
R \\
1 \\
O=C-\mathrm{NH}_{2}
\end{gathered}
$$

Strong absorption peak at $3334 \mathrm{~cm}^{-1}$ is the absorption band of stretching vibration $v(\mathrm{~N}-\mathrm{H})$ with hydrogen-bonding association. Strong absorption peaks at 1778,1752 and $1721 \mathrm{~cm}^{-1}$ are the absorption bands of stretching vibration $v(\mathrm{C}=\mathrm{O})$. Absorption peak at $1461 \mathrm{~cm}^{-1}$ is the absorption band of deformation vibration $\delta(\mathrm{N}-\mathrm{H})$. Strong absorption peak at $1053 \mathrm{~cm}^{-1}$ is the absorption band of stretching vibration $v(\mathrm{C}-\mathrm{N})$. These characteristic absorption peaks appeared at the same time, which 
showed that the composition of the sample contained aliphatic secondary amide. Its structure formula

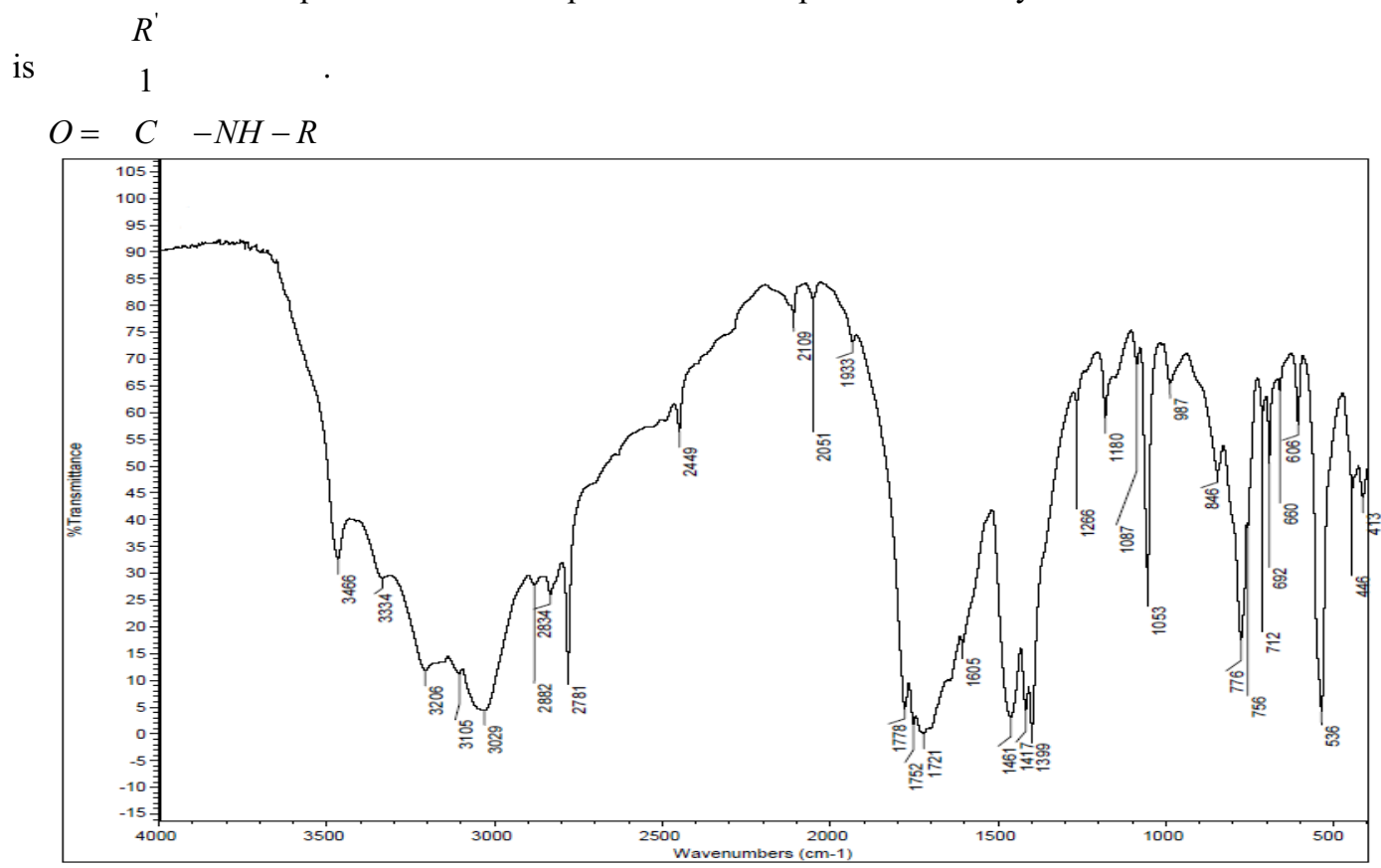

Figure 2. Fourier infrared spectra of deposits.

The infrared spectrograms of the deposits, biuret and cyanuric acid are compared in Figure 3. The results show that the matching degree of deposits and cyanuric acid is as high as $70 \%$ above, so we can primarily infer that the main ingredient in deposits is cyanuric acid.

\subsection{Quantitative analysis}

Figure 4 shows the chromatograms of deposits dissolved in methanol. Mass spectrometry results show that, the deposits contain biuret, urea and cyanuric acid. What's more, biurea, which haven't been observed in deposits ever, is also detected here. Hence, the reaction related biurea should be taken into account on the research of deposits in the future.

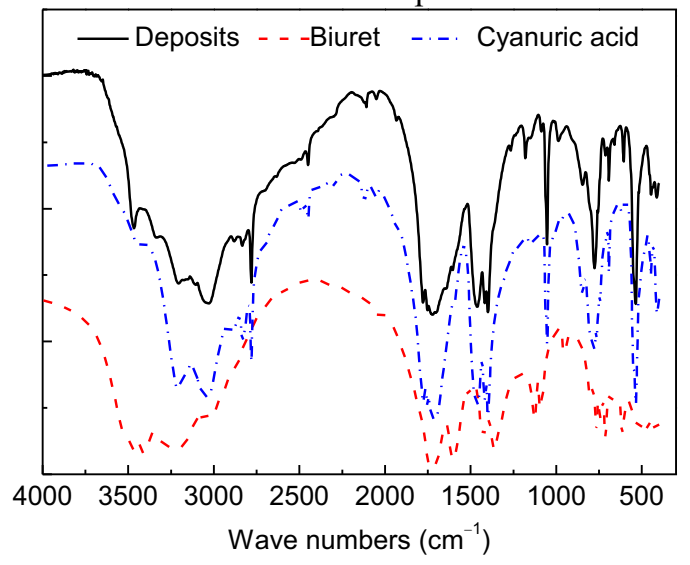

Figure 3. Infrared spectrum comparison results.

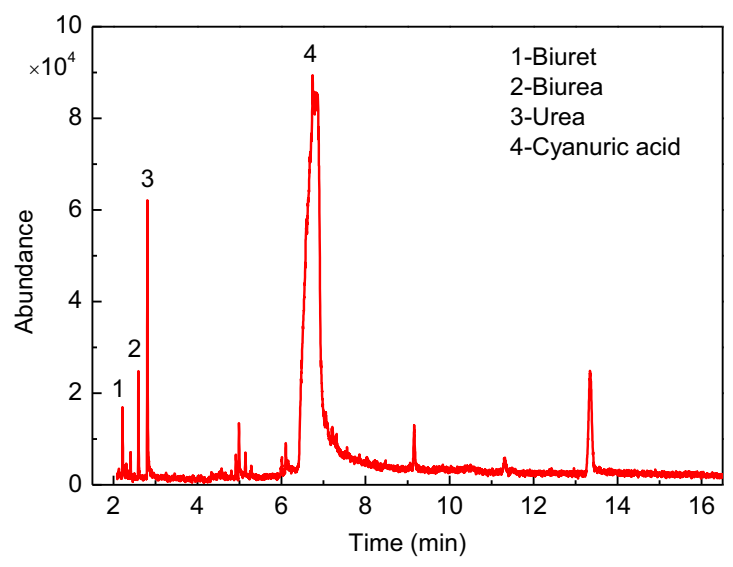

Figure 4. Chromatograms of the deposits.

According to the results of the area percentage, cyanuric acid has the largest peak area (about $85 \%$ ), followed by urea (about $4 \%$ peak area), and the content of biuret and biurea is scarce. Similarly, 
Paul Way [18] has analyzed multiple deposits ever by HPLC method and found that the content of cyanuric acid in the deposits was about $70 \sim 95 \%$, urea was about $5 \sim 15 \%$, which is consistent with the results in this paper. But the small amount of biurea was not detected in Paul Way's research.

\section{Conclusions}

This paper puts forward a kind of analysis process to determine the composition of organic matter: element analysis is to determine the content of each element in the sample, infrared spectrum analysis is to determine the characteristic functional groups of the sample, and the GC-MS analysis is to determine the content of each component quantitatively. From the results shown above, the following items can be concluded:

(1) The deposits are mainly composed of urea and its by-products. But beyond that, the deposits also adsorbed metal impurities from fuel oil, lubricating oil, mechanical wear and urea water solution;

(2) The organic matter of the deposits contains aliphatic amide $\left(\begin{array}{c}R \\ 1\end{array}\right)$ and aliphatic

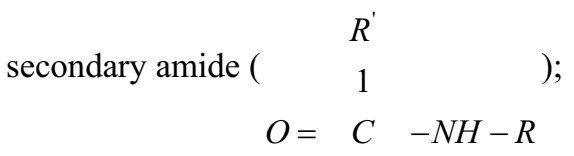

(3) According to the area percentage results of GC-MS analysis, cyanuric acid has the largest peak area (about $85 \%$ ), followed by urea (about $4 \%$ ), and the content of biuret and biurea is less.

\section{Acknowledgements}

The authors thank the support and grants by the National Natural Science Foundation of China (No. 51379165) and the National Special Foundation of China (No. L1422029). And we also appreciate the support of Key Laboratory of High Performance Ship Technology of Ministry of Education (Wuhan University of Technology).

\section{References}

1. Tan Feng, Wuhan: Wuhan University of Technology, 5 (2013)

2. Haoyu Wang, Wuhan: Wuhan University of Technology, 5 (2013)

3. Tim Johnson, SAE Paper, 130105 (2013)

4. M. Koebel and M. Elsener, Catalysis Today, 59, 335 345 (2000)

5. C. Scott Sluder and John M. E. Storey, SAE paper, (2004)

6. Gaia Piazzesi, Martin Elsener and Oliver Krocher, Applied Catalysis B: Environmental, 65, 169 174 (2006)

7. Noel W. Cant and Dean C. Chambers, Topics in Catalysis, 10, 13 20 (2000)

8. Peter M. Schaber, James Colson and Steven Higgins, Thermochimica Acta, 424, 131 142 (2004)

9. S.M. Thagard, A. Mihalcioiu and K. Takashima, IEEE Trans. Plasma Sci, 37, 444 448 (2009)

10. B.K. Boggs, R.L. King and G.G. Botte, Chem. Commun, 32, 4859 4861 (2009)

11. R. Lan, S. Tao and T.S. Irvine, Energy Environ. Sci, 3, 438 441 (2010)

12. A.N. Rollinson, G.L. Rickett and V. A Lea-Langton, Appl. Catal. B, 106, 304 315 (2011)

13. A.N. Rollinson, J. Jones and V. Dupont, Energy Environ. Sci, 4, 1216 1244 (2011)

14. Jenny M. Jonesa and Andrew N. Rollinson, Thermochimica Acta, 565, 39 45 (2013)

15. Saito S, Shinozaki R and Suzuki A, SAE Paper, 01, 3248 (2003)

16. Seo J, SAE Paper, 01, 1135 (2011)

17. Chen Yue, Lu Lin, Shen Jie, Chinese Internal Combustion Engine Engineering, 2, 36 (2015)

18. Paul Way, Karthik Viswanathan and Phebe Preethi, SAE Paper, 01, 0633 (2009) 